\title{
Analysis of sub-stoichiometric hydrogenated silicon oxide films for surface passivation of crystalline silicon solar cells
}

Florian Einsele, Wolfhard Beyer, and Uwe Rau

Citation: Journal of Applied Physics 112, 054905 (2012);

View online: https://doi.org/10.1063/1.4749415

View Table of Contents: http://aip.scitation.org/toc/jap/112/5

Published by the American Institute of Physics

\section{Articles you may be interested in}

Amorphous silicon oxide window layers for high-efficiency silicon heterojunction solar cells Journal of Applied Physics 115, 024502 (2014); 10.1063/1.4861404

Nature of doped $a-\mathrm{Si}: \mathrm{H} / c-\mathrm{Si}$ interface recombination Journal of Applied Physics 105, 103707 (2009); 10.1063/1.3129578

Passivation mechanism in silicon heterojunction solar cells with intrinsic hydrogenated amorphous silicon oxide layers

Journal of Applied Physics 121, 085306 (2017); 10.1063/1.4977242

Application of hydrogenated amorphous silicon oxide layers to $c-S i$ heterojunction solar cells

Applied Physics Letters 91, 133508 (2007); 10.1063/1.2790815

Optimized amorphous silicon oxide buffer layers for silicon heterojunction solar cells with microcrystalline silicon oxide contact layers

Journal of Applied Physics 113, 134501 (2013); 10.1063/1.4798603

Silicon heterojunction solar cell with passivated hole selective $\mathrm{MoO}_{\mathrm{X}}$ contact

Applied Physics Letters 104, 113902 (2014); 10.1063/1.4868880

\section{Scilight}

Sharp, quick summaries illuminating the latest physics research

\section{Sign up for FREE!}

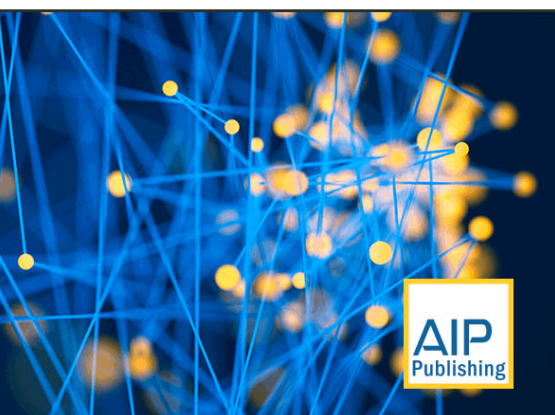




\title{
Analysis of sub-stoichiometric hydrogenated silicon oxide films for surface passivation of crystalline silicon solar cells
}

\author{
Florian Einsele, ${ }^{1}$ Wolfhard Beyer, ${ }^{1,2, a)}$ and Uwe Rau ${ }^{1}$ \\ ${ }^{1}$ IEK-5 Photovoltaik, Forschungszentrum Jülich GmbH, 52425 Jülich, Germany \\ ${ }^{2}$ Malibu GmbH \& Co. KG, 33609 Bielefeld, Germany
}

(Received 3 March 2012; accepted 9 August 2012; published online 7 September 2012)

\begin{abstract}
Thermal stability of passivating layers in amorphous/crystalline silicon (a-Si/c-Si) heterojunction solar cells is crucial for industrial processing and long-term device stability. Hydrogenated amorphous silicon $(\mathrm{a}-\mathrm{Si}: \mathrm{H})$ yields outstanding surface passivation as atomic hydrogen saturates silicon dangling bonds at the a-Si/c-Si interface. Yet, a-Si surface passivation typically starts to degrade already at annealing temperatures in the range of 200 to $250{ }^{\circ} \mathrm{C}$ depending on annealing time, and optical absorption in front layers of a-Si reduces the short circuit current density. We show that oxygen incorporation into a-Si:H films enhances the thermal stability of the passivation and reduces parasitic absorption. We further show that for good passivation of the a-Si/c-Si interface, a compact material structure of the a-Si:O:H films is required where atomic hydrogen is the dominating type of diffusing hydrogen species. For plasma deposited a-Si:O:H films, oxygen incorporation of up to 10 at. \% leads to an increase of the optical band gap while the hydrogen concentration is almost constant at approximately 10 at. \%. For oxygen concentrations below 3\%, the films yield surface recombination velocities as low as $10 \mathrm{~cm} / \mathrm{s}$ on p-type wafers, and the temperature stability improves by about $50 \mathrm{~K}$ compared to pure a-Si:H. For films with relatively low oxygen content, hydrogen effusion spectra and Fourier transform infrared spectroscopy (FTIR) indicate a compact microstructure where only atomic $\mathrm{H}$ diffuses. For oxygen concentrations above $3 \%$, the passivation quality reduces and $\mathrm{H}$ effusion and FTIR suggest the formation of an open, void-rich material where molecular $\mathrm{H}_{2}$ diffuses. In this case, annealing above $400{ }^{\circ} \mathrm{C}$ results in improved interface passivation, presumably due to a densification of the material. Likely, this densification results in an increased density of atomic $\mathrm{H}$, which saturates Si dangling bonds near the c-Si interface. (c) 2012 American Institute of Physics. [http://dx.doi.org/10.1063/1.4749415]
\end{abstract}

\section{INTRODUCTION}

Heterojunction solar cells of amorphous and crystalline silicon are a promising candidate for near-future high efficiency solar cells in mass production. Recently, a record cell efficiency of $23.7 \%$ (on $100 \times 100 \mathrm{~mm}^{2}$ ) has been presented ${ }^{1}$ and several groups have achieved efficiencies of well above $20 \% .^{2,3}$ Unlike many other high efficiency concepts, the silicon heterojunction concept is based on a rather simple processing scheme consisting of plasma enhanced chemical vapour deposition (PECVD), sputtering and screen printing steps, and all processing steps are carried out at temperatures below 200 to $250{ }^{\circ} \mathrm{C}$. The high efficiencies likely originate from low minority carrier recombination rates at the c-Si wafer surfaces passivated by thin layers of intrinsic amorphous silicon (a-Si:H). Without passivation, silicon surface states related to unsaturated and reconstructed dangling bonds are likely causing a rather high surface recombination rate. Besides amorphous silicon, several other amorphous siliconbased alloys have been investigated, like a-SiC:H and a-Si:O:H. In the present article, we focus on the latter alloy with oxygen concentrations ranging from $0 \%$ to $10 \%$. One advantage of oxygen addition is that the optical bandgap is increased and that the absorption in the visible light range is reduced.

a)Telephone: +49 2461 61-3925. Fax: -3735. e-mail: w.beyer@fz-juelich.de.
After the deposition of a-Si:H or a-Si:O:H passivation layers, annealing steps above $T=200^{\circ} \mathrm{C}$ are commonly applied in order to enhance the passivation quality. ${ }^{4,5}$ Apart from conventional hotplate heating, also short time microwave heating has shown beneficial effects on the surface passivation. ${ }^{5}$ These results suggest that $\mathrm{H}$ plays a dominant role in the surface passivation of $\mathrm{c}-\mathrm{Si}$ since oxygen or silicon do not diffuse significantly at the annealing temperatures commonly applied. The importance of diffusing atomic $\mathrm{H}$ near the c-Si/a-Si:H interface for a successful passivation of c-Si dangling bonds has also been pointed out elsewhere. ${ }^{6}$ Since hydrogen may diffuse within these materials in atomic or molecular form with (likely) very different passivation properties, we compare the passivation properties of such films with the material microstructure as detected by infrared absorption and hydrogen effusion measurements.

\section{SAMPLE PREPARATION AND CHARACTERIZATION METHODS}

The films were deposited in a PECVD reactor from gas mixtures of silane $\mathrm{SiH}_{4}$, carbon dioxide $\mathrm{CO}_{2}$, and hydrogen $\mathrm{H}_{2}$. The process parameters, given in Table I, are chosen in a range typical for high quality amorphous passivation layers. ${ }^{4,7}$ In order to adjust the oxygen concentration in the films, we varied the gas fraction 
TABLE I. Process parameters for the plasma-enhanced CVD of a-Si:O:H films.

\begin{tabular}{lccc}
\hline \hline Parameter & Symbol & Unit & Value \\
\hline Plasma frequency & $\mathrm{v}_{\mathrm{p}}$ & $\mathrm{MHz}$ & 81.4 \\
Plasma power density & $P$ & $\mathrm{~mW} / \mathrm{cm}^{2}$ & 13 \\
Deposition rate & $r$ & $\mathrm{~nm} / \mathrm{s}$ & 0.2 \\
Substrate temperature & $T_{\mathrm{S}}$ & ${ }^{\circ} \mathrm{C}$ & 200 \\
Hydrogen gas flow & {$\left[\mathrm{H}_{2}\right]$} & $\mathrm{sccm}$ & 20 \\
$\mathrm{CO}_{2}+\mathrm{SiH}_{4}$ gas flow & {$\left[\mathrm{CO}_{2}\right]+\left[\mathrm{SiH}_{4}\right]$} & $\mathrm{sccm}$ & 20 \\
\hline \hline
\end{tabular}

$$
f_{G}=\frac{\left[\mathrm{CO}_{2}\right]}{\left[\mathrm{CO}_{2}\right]+\left[\mathrm{SiH}_{4}\right]}
$$

of $\mathrm{CO}_{2}$ in the process gas mixture.

For the deposition on c-Si substrates, we used doubleside polished, $1-4 \Omega \mathrm{cm},\langle 100\rangle$ oriented, float-zone p-type wafers. Prior to deposition, the wafers were cleaned in a hydrogen peroxide based wet chemical cleaning process with a subsequent dip in hydrofluoric acid.

For the compositional characterization of the a-Si:O:H films, we used Rutherford backscattering (RBS) measurements and secondary ion mass spectrometry (SIMS). Photothermal deflection spectroscopy (PDS) yields the optical absorption coefficient near the band gap, whereas Fouriertransform infrared spectroscopy (FTIR) provides information about $\mathrm{Si}-\mathrm{H}$ and $\mathrm{Si}-\mathrm{O}$ diatomic vibration modes. The analysis of the $\mathrm{Si}-\mathrm{H}$ stretching modes in a-Si:H is known to yield an important structural information, since the $\mathrm{Si}-\mathrm{H}$ stretching mode at $2000 \mathrm{~cm}^{-1}$ is attributed to hydrogen incorporated in a compact material while the $\mathrm{Si}-\mathrm{H}$ stretching mode near $2100 \mathrm{~cm}^{-1}$ was attributed to hydrogen bonded at internal silicon surfaces (voids). ${ }^{8,9}$ In a-Si:O:H films, there is a complication, however, since the $\mathrm{Si}-\mathrm{H}$ stretching mode may also be shifted to higher energy by oxygen backbonds. ${ }^{10}$ Besides information about the $\mathrm{H}$ concentration, hydrogen effusion measurements also yield structural information about the material, since effusion of molecular hydrogen through interconnected voids gives completely different effusion spectra compared to $\mathrm{H}$ effusion related to the diffusion of atomic hydrogen. Quasi steady-state photoconductance (QSSPC) decay measurements yield effective minority carrier lifetimes of passivated c-Si wafers as a measure of surface passivation quality.

\section{BASIC CHARACTERIZATION OF AS-DEPOSITED MATERIAL}

\section{A. Film composition and optical properties}

The oxygen concentration $c_{\mathrm{O}}$ [at. \%] and the atomic carbon density $N_{\mathrm{C}}\left[\mathrm{cm}^{-3}\right]$ of a-Si:O:H films deposited at different gas fractions $f_{\mathrm{G}}$ is shown in Figs. 1(a) and 1(b), respectively. These concentration values were determined by SIMS measurements using RBS calibration standards. To convert atomic density into concentration values, a silicon atomic density of $5 \times 10^{22} \mathrm{~cm}^{-3}$ was employed. We find that the carbon concentration is about two orders of magnitude lower than the oxygen concentration, i.e., from the plasma-decomposed $\mathrm{CO}_{2}$

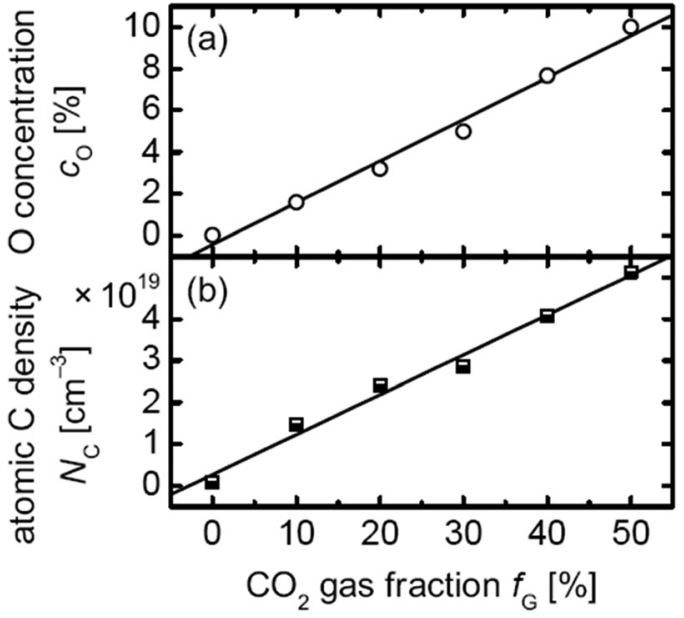

FIG. 1. (a) The oxygen concentration $c_{\mathrm{O}}$ rises linearly with the fraction $f_{\mathrm{G}}$ of $\mathrm{CO}_{2}$ in the $\mathrm{CO}_{2}-\mathrm{SiH}_{4}$ gas mixture. (b) The carbon atomic density $N_{\mathrm{C}}$ lies about two orders of magnitude below the $\mathrm{O}$ concentration (using the $\mathrm{Si}$ atomic density of $5 \times 10^{22} \mathrm{~cm}^{-3}$ ).

gas primarily oxygen is incorporated into the material. Both oxygen and carbon concentrations depend linearly on $f_{\mathrm{G}}$.

As shown in Fig. 2(a), the energy dependence of the absorption coefficient $\alpha$ (measured by PDS) shifts towards higher photon energies $E$ with increasing $c_{\mathrm{O}}$. As a consequence, the optical band gap $E_{04}$ (defined as the energy where $\alpha=10^{4} \mathrm{~cm}^{-1}$ ) increases from about 1.9 to $2.1 \mathrm{eV}$ for an increase of $c_{\mathrm{O}}$ from $0 \%$ to $10 \%$, as shown in Fig. 2(b). If a-Si:O:H is applied as front side emitter passivation, such a wider optical band gap is favourable in view of reduced optical absorption.

\section{B. FTIR spectroscopy of diatomic vibrations}

We measured FTIR absorption spectra on approximately $400 \mathrm{~nm}$ thick a-Si:O:H films deposited on c-Si substrates, and we used the correction factor $K=(1.72-0.0011 \omega d)^{-1}$ for data evaluation. ${ }^{11}$ The resulting absorption spectra $\alpha(\omega)$ of Fig. 3 show three dominant absorption bands as listed in Table II. As no O-H stretching modes show up near $3500 \mathrm{~cm}^{-1}$, apparently little hydrogen is bound to oxygen.

According to Ref. 8, the integrated absorption

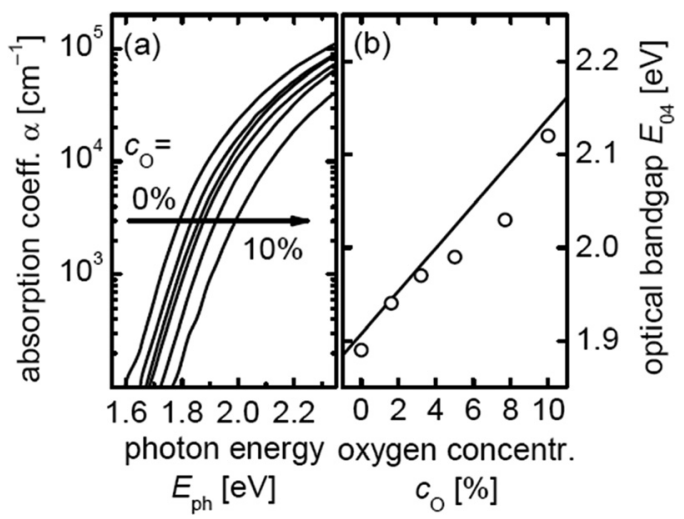

FIG. 2. (a) The energy dependence of the PDS absorption coefficient $\alpha$ shifts towards higher photon energy $E$ with increasing oxygen concentration $c_{\mathrm{O}}$. (b) The optical bandgap $E_{04}$ (i.e., the energy where $\alpha=10^{4} \mathrm{~cm}^{-1}$ ) increases with rising $c_{\mathrm{O}}$. 




FIG. 3. FTIR absorption coefficient $\alpha$ as a function of frequency $\omega$ of the $\mathrm{Si}-\mathrm{H}$ bending modes near $\omega=640 \mathrm{~cm}^{-1}, \mathrm{Si}-\mathrm{O}-\mathrm{Si}$ stretching modes near $1000 \mathrm{~cm}^{-1}$, and Si-H stretching modes from 1900 to $2200 \mathrm{~cm}^{-1}$ for different oxygen concentrations $c_{\mathrm{O}}$. Ordinate scaling given by double arrows.

$$
I=\int(\alpha(\omega) / \omega) \mathrm{d} \omega
$$

of an absorption band is proportional to the atomic density $N=I A$ of the involved species, where $A$ is the absorption (oscillator) strength of the respective mode. As shown in Fig. 4(a), the integrated absorption $I_{\mathrm{O}}$ of the $\mathrm{Si}-\mathrm{O}-\mathrm{Si}$ stretching mode near $1000 \mathrm{~cm}^{-1}$ rises linear with $c_{\mathrm{O}}$. For an atomic density of $5 \times 10^{22} \mathrm{~cm}^{-3}$, we obtain an absorption strength $A_{\mathrm{O}}=(1.4 \pm 0.2) \times 10^{19} \mathrm{~cm}^{-2}$ which is in agreement with literature data. ${ }^{14,15}$ Figure 4(b) shows that also the peak frequency $\omega_{\mathrm{Ox}}$ of the $\mathrm{Si}-\mathrm{O}$ vibration increases with rising $c_{\mathrm{O}}$. From $\mathrm{c}_{\mathrm{O}}=2 \%$ to $10 \%, \omega_{\mathrm{Ox}}$ increases from 980 to $1020 \mathrm{~cm}^{-1}$, This effect which has been explained by O backbonding or a variation of the $\mathrm{Si}-\mathrm{O}-\mathrm{Si}$ bond angles. ${ }^{16-20}$

For $c_{\mathrm{O}}=0 \%(\mathrm{a}-\mathrm{Si}: \mathrm{H})$, the FTIR spectra of Fig. 3 show one distinct $\mathrm{Si}-\mathrm{H}$ stretching mode at $\omega_{0}=2000 \mathrm{~cm}^{-1}$, typical for a-Si:H of a compact microstructure. ${ }^{8}$ With increasing $c_{\mathrm{O}}$, the mode at $\omega_{0}$ decreases and a mode at $\omega_{1}=2090 \mathrm{~cm}^{-1}$ appears. Such a transition of the predominant $\mathrm{Si}-\mathrm{H}$ stretching mode in a-Si:H is frequently observed. It has been attributed to a rising fraction of $\mathrm{Si}-\mathrm{H}$ bonds located at inner surfaces of voids in the material. Different dielectric constants of the bulk and near surfaces explain the shift of the vibrational frequency towards higher values. ${ }^{8,9,21}$ However, for a-Si:O:H, a shift of the Si-H vibrational frequency can also be caused by the induction effect of oxygen atoms backbonded to the Si-H bonds. ${ }^{10,19}$ In this case, the higher electronegativity of $\mathrm{O}$ (as compared to silicon) leads to distinct stretching modes at frequencies $\omega_{n}$ which depend on the

TABLE II. Main absorption bands observed in FTIR spectroscopy for PECVD a-Si:O:H films.

\begin{tabular}{lcc}
\hline \hline Frequency $\omega\left[\mathrm{cm}^{-1}\right]$ & Type of absorption mode(s) & Literature \\
\hline$\approx 640$ & Si-H wagging & Ref. 12 \\
$\approx 1000$ & Si-O-Si stretching & Refs. 10 and 12 \\
1900 to 2200 & Si-H stretching & Refs. 8 and 13 \\
\hline \hline
\end{tabular}

number $n$ of back-bonded $\mathrm{O}$ atoms. ${ }^{19}$ As a consequence, for a-Si:O:H, both the formation of voids and $\mathrm{O}$ back-bonding may lead to a redistribution of the $\mathrm{Si}-\mathrm{H}$ stretching vibration, as discussed before. ${ }^{22}$ A conclusion from IR absorption measurements on the presence of voids in a-Si:O:H alloys appears only possible if void-related shifts of the Si-H vibrational frequency and backbonding related shifts can be separated. This will be discussed in detail in Sec. IV.

\section{CHANGES OF FTIR Si-H STRETCHING ABSORPTION MODES WITH INCREASING OXYGEN CONCENTRATION AND UPON ANNEALING}

\section{A. Experimental procedure}

Aiming to separate void and backbonding related shifts of the Si-H stretching modes, we studied FTIR absorption of a-Si:O:H films in greater detail. For this purpose, we prepared $800 \mathrm{~nm}$ thick a-Si:O:H films with $c_{\mathrm{O}}=5$ and $10 \%$ and studied effects of annealing by heating the samples in the evacuated effusion system at a heating rate of $\beta=20 \mathrm{~K} / \mathrm{min}$ up to temperatures of 400 and $600{ }^{\circ} \mathrm{C}$.

\section{B. Spectra of unannealed and annealed films}

The FTIR absorption spectra in the range of 1900 to $2350 \mathrm{~cm}^{-1}$ of the as-deposited films as well as for various annealing steps are shown in Fig. 5. The spectra of the asdeposited material in Figs. 5(a) and 5(d) differ somewhat from those in Fig. 3 due to different film thicknesses and deposition process variations. We fitted Gaussian peaks (equal widths for each sample and temperature) to the absorption spectra, centered near the frequencies $\omega$ given in the second column (for compact material) and third column (void-rich material) of Table III. For as deposited material of 5 at. \% oxygen content, the $\mathrm{Si}-\mathrm{H}$ stretching absorption band is deconvoluted into two peaks of almost equal height centered near 2000 and $2090 \mathrm{~cm}^{-1}$. For as deposited material of $c_{\mathrm{O}}=10 \%$, the main absorption shows up near $\omega=2090 \mathrm{~cm}^{-1}$ with a minor peak near $2000 \mathrm{~cm}^{-1}$ in agreement with the spectra of Fig. 3. As discussed in Sec. III, the mode at $2000 \mathrm{~cm}^{-1}$ is typical for compact, oxygen-free a-Si:H, whereas the mode at $2090 \mathrm{~cm}^{-1}$ can be explained by both $\mathrm{Si}-\mathrm{H}$ at surfaces of inner voids and $\mathrm{O}$ back-bonding of $\mathrm{Si}-\mathrm{H}$ vibrators in a compact

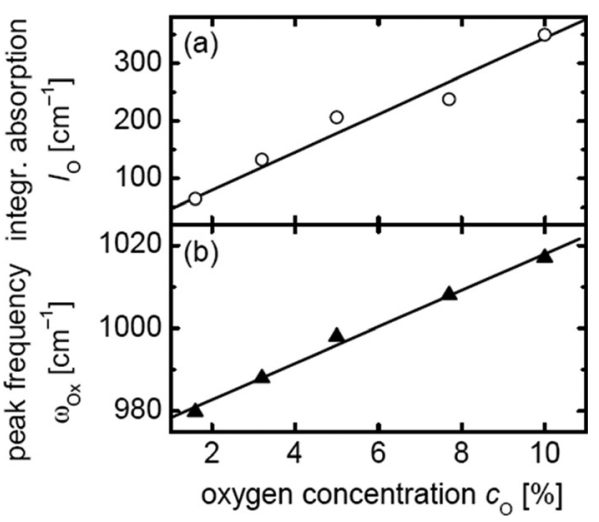

FIG. 4. (a) Integrated absorption $I_{\mathrm{O}}$ and (b) peak frequency $\omega_{\mathrm{Ox}}$ of the $\mathrm{Si}-\mathrm{O}-\mathrm{Si}$ stretching modes as a function of oxygen concentration, extracted from the FTIR data of Fig. 3. 


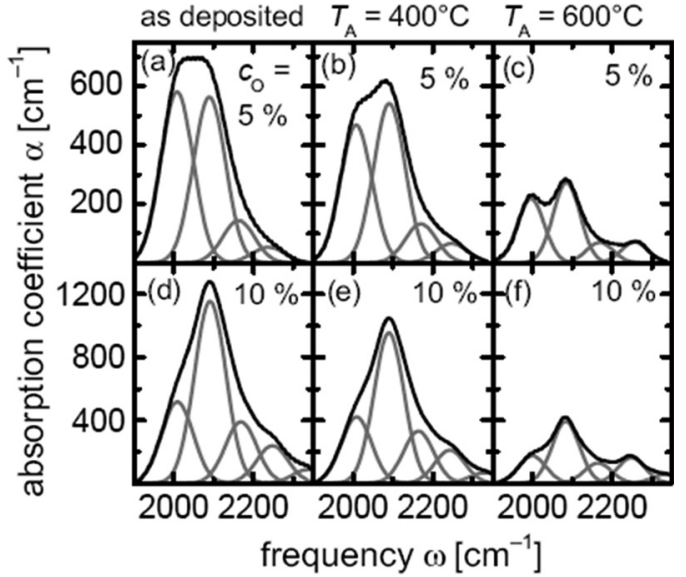

FIG. 5. ((a)-(f)) Si-H bending mode absorptions between $\omega=1900$ and $2400 \mathrm{~cm}^{-1}$ and Gaussian peak fits for a-Si:O:H films with oxygen concentrations of $c_{\mathrm{O}}=5 \%$ and $10 \%$ : Unannealed films (as-deposited material) and annealed in vacuum at a heating rate of $\beta=20 \mathrm{~K} / \mathrm{min}$ up to $T_{\mathrm{A}}=400^{\circ} \mathrm{C}$ and $600^{\circ} \mathrm{C}$.

material. Higher frequency peaks in Fig. 5 are explained by manifold back-bonded oxygen $\left(\mathrm{H}-\mathrm{Si}-\mathrm{Si}_{3-n} \mathrm{O}_{n}\right) .{ }^{19}$ In Table III, $n=0-3$ is assigned to the peak frequencies $\omega_{n}$ for compact material (second column) and void-rich material (third column). For simplicity, we set the peak for $n$-fold oxygen back-bonded $\mathrm{Si}-\mathrm{H}$ in void-rich material equal to the peak for $(n+1)$-fold oxygen back-bonded $\mathrm{Si}-\mathrm{H}$ in compact material. We note, however, that by reasons of bond lengths of $\mathrm{Si}-\mathrm{Si}$ and $\mathrm{Si}-\mathrm{O}-\mathrm{Si}$ bonds it seems quite unlikely that for high oxygen concentrations a compact a-Si:O:H in the sense of compact a-Si:H can exist at all.

\section{Mean Si-H stretching frequency}

If we ideally assume random $\mathrm{O}$ distributions in the material, we obtain the probabilities ${ }^{19}$

$$
p_{n}(x)=\frac{3 !}{(3-n) ! n !}\left(1-\frac{x}{2}\right)^{3-n}\left(\frac{x}{2}\right)^{n}
$$

for $n$-fold $\mathrm{O}$ back-bonding in dependence of the stoichiometry parameter $x$. From the integrated absorption $I_{\mathrm{O}}$, the absorption strength $A_{\mathrm{O}}=1.4 \times 10^{19} \mathrm{~cm}^{-1}$ of the $\mathrm{Si}-\mathrm{O}-\mathrm{Si}$ mode, and the atomic density $N=5 \times 10^{22} \mathrm{~cm}^{-3}$, we obtain $x=A_{\mathrm{O}} I_{\mathrm{O}} /(N-$ $A_{\mathrm{O}} I_{\mathrm{O}}$ ). Defining a mean $\mathrm{Si}-\mathrm{H}$ stretching frequency ${ }^{22}$

$$
\omega_{\mathrm{m}}=\sum_{n} p_{n} \omega_{n}=\sum_{n} I_{n} \omega_{n} / \sum_{n} I_{n}
$$

TABLE III. Peak frequencies of $\mathrm{Si}-\mathrm{H}$ stretching modes and attributed number of back-bonded $\mathrm{O}$ atoms for compact and void-rich material.

\begin{tabular}{lcc}
\hline \hline & \multicolumn{2}{c}{ Si-H oscillation frequency $\omega_{n}$} \\
\cline { 2 - 3 } $\begin{array}{l}\text { Number } n \text { of back-bonded } \\
\text { oxygen atoms }\end{array}$ & Compact material & Void-rich material \\
\hline 0 & 2000 & 2090 \\
1 & 2090 & 2165 \\
2 & 2165 & 2250 \\
3 & 2250 & 2330 \\
\hline \hline
\end{tabular}

we can conveniently compare calculated and experimental data. The solid lines in Fig. 6 depict the mean frequencies $\omega_{\mathrm{m}}$ for compact and void-rich material, respectively, calculated by Eq. (4) using the values for $n$ and $\omega_{n}$ from Table III. As expected, $\omega_{\mathrm{m}}$ rises with increasing $I_{\mathrm{O}}$ (i.e., with increasing oxygen concentration $c_{\mathrm{O}}$ ). Both lines represent idealized cases where (a) the material structure is independent of $I_{\mathrm{O}}$ (or $c_{\mathrm{O}}$ ), (b) the $\mathrm{O}$ atoms are randomly distributed within the films, and (c) Si-H is either located completely in the bulk (compact material) or completely at void surfaces (void-rich material). From these simplifications, it is clear that the calculations represent rather qualitatively lower and upper boundaries for $\omega_{\mathrm{m}}$. The experimental data points for $T_{\mathrm{S}}=50^{\circ} \mathrm{C}$ (void-rich material) of Ref. 22 lie fully on the upper line. The experimental data points of this work $\left(T_{\mathrm{S}}=200^{\circ} \mathrm{C}\right.$ ) and the previous one ${ }^{22}$ (for $T_{\mathrm{S}}=250^{\circ} \mathrm{C}$ ) lie near or between these curves. Already for low $I_{\mathrm{O}}$, these latter experimental values depart from the (lower) line for compact material and converge towards the (upper) line for void-rich material for higher oxygen concentrations. This indicates an increasingly open material structure for higher $I_{\mathrm{O}}$, which is in good agreement with the $\mathrm{H}$ effusion results in Sec. V. These results also suggest that under our present and previous deposition conditions, oxygen bearing compact material may exist only in the low oxygen concentration range.

Concerning details of the fitted FTIR absorption spectra as a function of annealing (Figs. 5(b), 5(c), 5(e) and 5(f)), we note that according to the present model the situation is complicated. Several annealing effects may be expected: diffusion of hydrogen to possibly stronger bonding sites with $\mathrm{O}$ back-bonds or into isolated voids, material reconstruction, formation of isolated voids from interconnected voids, etc. Obviously, further work appears necessary.

As hydrogen diffuses out, the total $\mathrm{Si}-\mathrm{H}$ absorption decreases as a function of annealing. As most stable configurations of hydrogen appear those configurations which cause the absorptions near 2090 and $2250 \mathrm{~cm}^{-1}$. Since surface bound hydrogen (without oxygen backbonds) is unlikely a

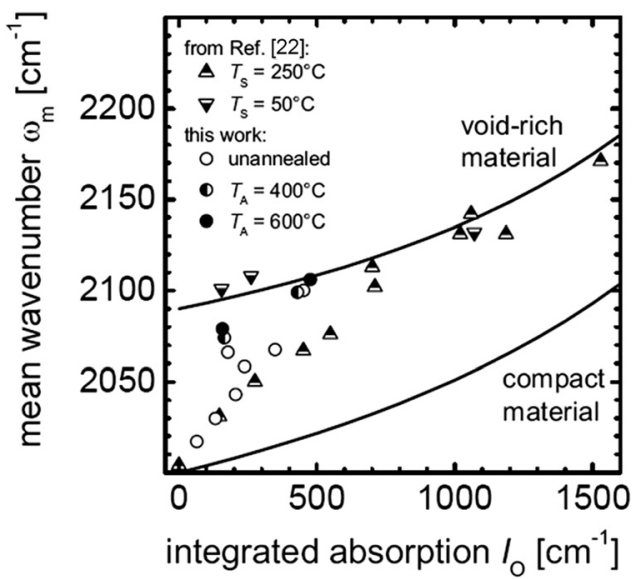

FIG. 6. Mean absorption frequency $\omega_{\mathrm{m}}$ versus integrated absorption $I_{\mathrm{O}}$ of the $\mathrm{Si}-\mathrm{O}-\mathrm{Si}$ absorption mode for unannealed samples and samples annealed at $T_{\mathrm{A}}=400^{\circ} \mathrm{C}$ and $600{ }^{\circ} \mathrm{C}$, respectively (substrate temperature is always $T_{\mathrm{S}}=200^{\circ} \mathrm{C}$ ). Also shown are data from Ref. 22 of samples deposited at different substrate temperatures $T_{\mathrm{S}}=50^{\circ} \mathrm{C}$ and $250^{\circ} \mathrm{C}$, repectively. Lines were calculated assuming void-rich and compact material, respectively. 
very stable $\mathrm{Si}-\mathrm{H}$ configuration, this result supports that oxygen backbonding enhances $\mathrm{H}$ stability.

We note, furthermore, that after annealing at $600{ }^{\circ} \mathrm{C}$, the peaks become significantly sharper. The widths of the Gaussian peaks reduce from about $95 \mathrm{~cm}^{-1}$ to $80 \mathrm{~cm}^{-1}$. A more defined bonding of hydrogen may explain this behaviour, i.e., only hydrogen in strongest $\mathrm{Si}-\mathrm{H}$ bonds remains in the sample after annealing.

\section{HYDROGEN EFFUSION}

\section{A. Experimental procedure}

In the Jülich effusion setup, a-Si:O:H films on c-Si substrates are heated in vacuum at a constant heating rate $\beta=20 \mathrm{~K} / \mathrm{min}$ from room temperature to $1050{ }^{\circ} \mathrm{C}$. After calibration with a known gas flow, the hydrogen partial pressure at the pumping port of the turbomolecular pump measured with a mass spectrometer yields the hydrogen effusion rate $\mathrm{d} N / \mathrm{d} t$ from the sample. ${ }^{23}$ The effusing species is known to be always $\mathrm{H}_{2}$. The effusion rate may be limited by several effects like the primary rupture of $\mathrm{Si}-\mathrm{H}$ bonds, the diffusion of atomic or molecular hydrogen to the film surface, and (in case of diffusion of hydrogen atoms) the recombination of $\mathrm{H}$ atoms to form $\mathrm{H}_{2}$ molecules at the film surface.

\section{B. Influence of film microstructure on the effusion of hydrogen}

It has been shown earlier that for a-Si:H films, effusion peaks near $400^{\circ} \mathrm{C}$ are typical for desorption of $\mathrm{H}_{2}$ from internal surfaces and rapid outdiffusion of $\mathrm{H}_{2}$ through interconnected voids, while peaks at temperatures above $500^{\circ} \mathrm{C}$ (film thickness $>100 \mathrm{~nm}$ ) are typical for diffusion of atomic $\mathrm{H}$ through the network. ${ }^{23}$ Thus, if $\mathrm{H}$ effusion spectra show both types of effusion peaks, a reconstruction of Si-Si bonds must take place where void-rich material is transformed to a more compact one. As the material densifies, diffusion by atomic $\mathrm{H}$ becomes apparently the major hydrogen transport process, as in the case for initially dense material. Network reconstruction effects have been confirmed by inert gas effusion of implanted $\mathrm{He}, \mathrm{Ne}$, and Ar showing peak shifts to higher temperature (HT) as a function of annealing for a-Si:H as well as for a-Si:O:H. ${ }^{24}$

In Fig. 7, the hydrogen effusion spectra for oxygen-free a-Si:H $\left(c_{\mathrm{O}}=0\right)$ show a single peak at $T_{\mathrm{M}}=510^{\circ} \mathrm{C}$ which is typical for a compact material of a thickness of about $0.4 \mu \mathrm{m}$, where the diffusion of atomic $\mathrm{H}$ limits the effusion process. With increasing oxygen concentration, this effusion peak shifts to higher temperature and, for $c_{\mathrm{O}}>4 \%$, a low temperature (LT) effusion peak near $430^{\circ} \mathrm{C}$ appears which is attributed to the presence of interconnected voids. This $\mathrm{H}$ effusion process is usually little limited by $\mathrm{H}$ diffusion and is commonly observed for a-Si:H films of high hydrogen content.

On the whole, the $\mathrm{H}$ effusion spectra of Fig. 7 get much broader with rising oxygen concentration. While for $c_{\mathrm{O}}=0$, $\mathrm{H}$ effusion finishes near $600^{\circ} \mathrm{C}$, it extends up to above $700{ }^{\circ} \mathrm{C}$ for films containing $10 \%$ of oxygen. An increase in the width of the effusion transients with rising oxygen con-

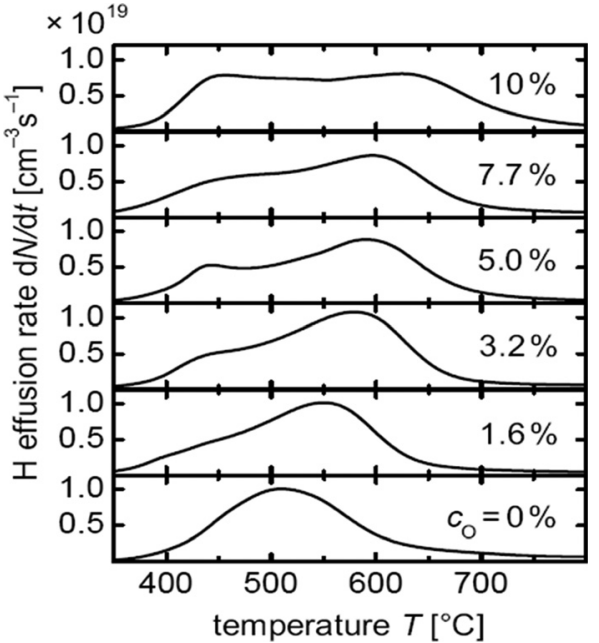

FIG. 7. $\mathrm{H}$ effusion spectra obtained by linear heating at a rate of $20 \mathrm{~K} / \mathrm{min}$. The peak of the effusion rate $\mathrm{d} N / \mathrm{d} t$ gets broader and shifts towards higher temperatures with increasing oxygen concentration $c_{\mathrm{O}}$. A low temperature effusion structure near $430^{\circ} \mathrm{C}$ evolves which is typical for the desorption of $\mathrm{H}_{2}$ from material with an interconnected void structure.

centration was also reported earlier, but then the LT effusion peak did not show up. A major conclusion from the $\mathrm{H}$ effusion spectra is that the material remains rather compact up to about 4 at. \% oxygen but gets void rich at higher oxygen concentrations, in agreement with the analysis of IR spectra presented in Sec. IV.

\section{Hydrogen content of a-Si:O:H}

The integral over the hydrogen effusion curve yields the absolute amount of $\mathrm{H}$ released during the effusion experiment. Assuming a negligible amount of residual $\mathrm{H}$ after heating to $1000^{\circ} \mathrm{C}$ (as supported by the $\mathrm{H}$ effusion spectra), we obtain the initial $\mathrm{H}$ concentration $c_{\mathrm{H}}$ of the films as given in Fig. 8(a). A weak trend towards higher $c_{\mathrm{H}}$ shows up for increasing $c_{\mathrm{O}}$. Fig. 8(a) also shows data points (for rf-plasma grown a-Si:O:H films) of the previous publication, ${ }^{22}$ revealing a good quantitative agreement with the present results.

\section{Diffusion-limited release of hydrogen}

In Fig. 8(b), the effusion peak maximum temperature $T_{\mathrm{M}}$ of the present work and the previous one ${ }^{22}$ are shown. In both cases, $T_{\mathrm{M}}$ shifts significantly to higher temperature with increasing oxygen concentration. However, the peak temperature in the previous publication is about $40^{\circ} \mathrm{C}$ higher. This latter result is in agreement with the assignment of this effusion peak to a diffusion-limited process, since the films of the present work are about $400 \mathrm{~nm}$ thick, while in the previous publication, the film thickness was between 1 and $1.5 \mu \mathrm{m}$. For diffusion limited effusion, the correlation

$$
\ln \left(\frac{D_{0}}{E_{D}}\right)-\frac{E_{D}}{k T_{M}}=\ln \left(\frac{d^{2} \beta}{\pi^{2} k T_{M}^{2}}\right)
$$

between diffusion prefactor $D_{0}$, diffusion energy $E_{\mathrm{D}}$, and the peak effusion temperature $T_{\mathrm{M}}$ has been found, ${ }^{25}$ with 


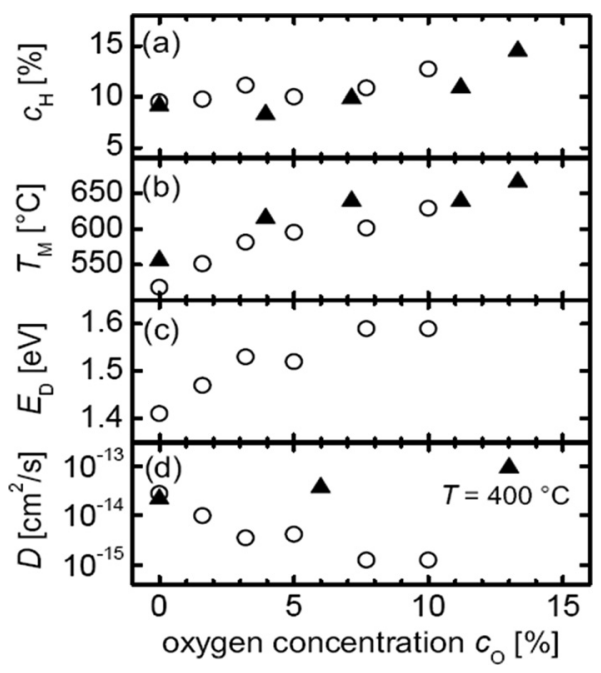

FIG. 8. Oxygen concentration dependence of (a) $\mathrm{H}$ concentration $c_{\mathrm{H}}$ obtained from $\mathrm{H}$ effusion, (b) $\mathrm{H}$ effusion peak temperature $T_{\mathrm{M}}$, (c) diffusion energy $E_{\mathrm{D}}$ evaluated from $\mathrm{H}$ effusion data using a constant diffusion prefactor $D_{0}=10^{-3} \mathrm{~cm}^{2} / \mathrm{s}$, (d) $\mathrm{H}$ diffusion coefficient $D$ for $T=400^{\circ} \mathrm{C}$ from $\mathrm{H}$ effusion and from SIMS interdiffusion experiments (open symbols: present work, closed symbols: Ref. 22).

heating rate $\beta$, film thickness $\mathrm{d}$, and Boltzmann constant $\mathrm{k}=8.617 \times 10^{-5} \mathrm{eV} / \mathrm{K}$, if the hydrogen diffusion coefficient follows an Arrhenius dependence:

$$
D(T)=D_{0} \exp \left(\frac{-E_{\mathrm{D}}}{\mathrm{k} T}\right) .
$$

The observed higher $T_{\mathrm{M}}$ for thicker films is in agreement with Eq. (5). It must be noted, however, that the diffusion coefficient $D(T)$ defined by $D_{0}$ and $E_{\mathrm{D}}$ is valid only for those $\mathrm{H}$ atoms which contribute to the maximum effusion rate. Hydrogen diffusion processes with lower $E_{\mathrm{D}}$ may be active for diffusion and effusion at temperatures below $T_{\mathrm{M}}$ while processes with higher $E_{\mathrm{D}}$ may be active at higher temperatures. These additional $\mathrm{H}$ diffusion processes result in a widening of the $\mathrm{H}$ effusion peak.

Using the theoretical diffusion prefactor of hydrogen in silicon $D_{0}=10^{-3} \mathrm{~cm}^{2} / \mathrm{s}$ for a-Si:H, ${ }^{23} \mathrm{Eq}$. (5) yields the $\mathrm{H}$ diffusion energy $E_{\mathrm{D}}$ from the HT effusion peak temperature $T_{\mathrm{M}}$ in Fig. 8(b). The resulting data in Fig. 8(c) show that the diffusion energy rises from $E_{\mathrm{D}} \approx 1.4$ to $1.6 \mathrm{eV}$ for oxygen concentrations from 0 to 10 at. $\%$. Likewise, the $\mathrm{H}$ diffusion coefficient at $\mathrm{T}=400{ }^{\circ} \mathrm{C}$, calculated from the same experimental data decreases, as shown in Fig. 8(d).

\section{E. Discussion of the $\mathrm{H}$ diffusion coefficient}

Previously, the $\mathrm{H}$ diffusion coefficient at $T=400{ }^{\circ} \mathrm{C}$ was also determined by SIMS measurements of hydrogen and deuterium interdiffusion in deuterium-implanted a-Si:O:H films. ${ }^{22}$ These data are also given in Fig. 8(d). While the $\mathrm{H}$ diffusion coefficients agree closely for films without oxygen, with increasing oxygen concentration the $\mathrm{H}$ diffusion coefficient measured by SIMS increases slightly while the one measured by the $\mathrm{H}$ effusion maximum decreases.

Heterogeneity in $\mathrm{H}$ incorporation is probably the reason for this latter behavior: At $T \approx 400{ }^{\circ} \mathrm{C}$, only some fraction of the incorporated hydrogen is presumably mobile, with the rather high $\mathrm{H}$ diffusion coefficient measured by SIMS H-D interdiffusion. A significant part of the incorporated hydrogen, however, has a lower effective diffusion coefficient, i.e., a higher average binding energy. One possible explanation is back-bonded $\mathrm{O}$ which is known to increase the $\mathrm{Si}-\mathrm{H}$ stretching mode frequency. This points to a higher force constant of the $\mathrm{Si}-\mathrm{H}$ bond. Conceivable is that also the $\mathrm{Si}-\mathrm{H}$ binding energy is enhanced by oxygen back bonding. A higher average $\mathrm{H}$ binding energy would also result if some $\mathrm{H}$ was bound to $\mathrm{O}$, however, (within the accuracy of our IR absorption measurements) no $\mathrm{O}-\mathrm{H}$ absorption was observed. Further reasons for the shift of the high temperature $\mathrm{H}$ effusion peak to higher temperature could be material reconstruction effects in parallel with hydrogen release ${ }^{26}$ and the presence of isolated voids where molecular hydrogen may get trapped. Clearly, more work appears necessary on this subject.

\section{SURFACE PASSIVATION OF CRYSTALLINE SILICON}

\section{A. Experimental procedure}

In order to evaluate the a-Si:O:H surface passivation effect for heterojunction solar cells, we deposited $50 \mathrm{~nm}$ films of a-Si:O:H on both sides of p-type c-Si wafers. A QSSPC Sinton lifetime tester ${ }^{27}$ operating in generalized mode yields the effective minority carrier lifetime $\tau_{\text {eff }}$ at one sun illumination. As the bulk lifetime $\tau_{\mathrm{b}}$ of the float-zone wafers is in the order of several milliseconds, $\tau_{\text {eff }}$ is basically limited by recombination at the surface. According to Ref. 28 , we determined the surface recombination velocity

$$
S=\frac{d}{2}\left[\tau_{\mathrm{eff}}-\frac{1}{D_{n}}\left(\frac{d}{\pi}\right)^{2}\right]^{-1}
$$

for a wafer thickness $d=250 \mu \mathrm{m}$ and an electron diffusion coefficient $D_{\mathrm{n}}=27 \mathrm{~cm} / \mathrm{s}$. From isochronal annealing experiments, information is obtained about the influence of postdeposition annealing on surface recombination. Therefore, wafers were heated on a hotplate in $20 \mathrm{~K}$ steps for $1 \mathrm{~min}$ each. This procedure results in an effective heating rate of $20 \mathrm{~K} / \mathrm{min}$, equal to the heating rate applied for hydrogen effusion.

\section{B. Incubation layer effect on surface passivation}

For $c_{\mathrm{O}}=0$ (a-Si:H), Fig. 9(a) shows surface recombination velocities $S$ in a range of 1000 to $2000 \mathrm{~cm} / \mathrm{s}$, hence a poor passivation of the c-Si surface. We attribute this result to the formation of a void-rich incubation layer, as also suggested by Fujiwara and Kondo. ${ }^{29}$ These authors explained the poor passivation quality by the growth of a defect-rich epitaxial layer near the interface. In general, nucleation layers are well known to appear and it is also known that these layers strongly depend on deposition conditions. ${ }^{30}$ As a reference, we investigated an a-Si: $\mathrm{H}$ film deposited at the plasma frequency $\nu_{\mathrm{p}}=13.56 \mathrm{MHz}$ and obtained good surface passivation with $S<15 \mathrm{~cm} / \mathrm{s}$ as shown in Fig. 9(b). Thus, in this case, little detrimental incubation layer effect is 


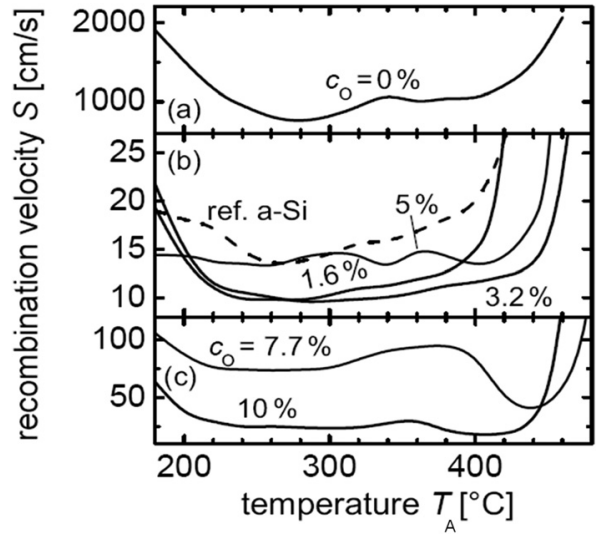

FIG. 9. Evolution of surface recombination velocity $S$ on p-type c-Si with annealing temperature $T_{\mathrm{A}}$ : (a) for $c_{\mathrm{O}}=0$, high $S$ results presumably from a low-quality incubation layer, (b) reference a-Si:H (plasma frequency $\nu_{\mathrm{p}}=13.56 \mathrm{MHz}$ ) and a-Si:O:H with $c_{\mathrm{O}} \leq 5 \%$ yield very low $S \leq 15 \mathrm{~cm} / \mathrm{s}$, (c) for $c_{\mathrm{O}}>5 \%, \mathrm{~S}$ is increased. Passivation improves for $450>T_{\mathrm{A}}>400^{\circ} \mathrm{C}$ due to material densification.

observable. We tentatively attribute this disappearance of a void-rich incubation layer to the higher ion bombardment at lower plasma frequency.

\section{High-quality passivation at moderate O concentrations}

In the very high frequency deposition regime used for the a-Si:O:H series (see Table I), already the introduction of small amounts of $\mathrm{CO}_{2}$ to the process gas inhibits or reduces the formation of the detrimental incubation layer. As a consequence, for $c_{\mathrm{O}}=1.6$ and 3.2\%, Fig. 9(b) depicts excellent passivation with $S \leq 10 \mathrm{~cm} / \mathrm{s}$, obtained after moderate annealing at temperatures $T_{\mathrm{A}}=250$ to $280^{\circ} \mathrm{C}$. We note that a similar low recombination velocity of $\mathrm{S} \leq 2.6 \mathrm{~cm} / \mathrm{s}$ was also reported by Ref. 7 for $\mathrm{SiO}: \mathrm{H}$ films of presumably similar composition and an annealing temperature of $250^{\circ} \mathrm{C}$. For our annealing procedure, the $\mathrm{H}$ diffusion length $L_{\mathrm{D}}=(D t)^{0.5} \approx 0.2 \mathrm{~nm}$ obtained from $\mathrm{H}$ effusion cannot explain an improved surface passivation due to $\mathrm{H}$ migration (data from Sec. V: $E_{\mathrm{D}} \approx 1.5 \mathrm{eV}, D_{0}=10^{-3} \mathrm{~cm}^{2} / \mathrm{s}$, $\left.D\left(T=265^{\circ} \mathrm{C}\right)=8.9 \times 10^{-18} \mathrm{~cm}^{2} / \mathrm{s}, t=60 \mathrm{~s}\right)$. However, the $\mathrm{H}$ diffusion coefficient determined by SIMS $^{22}$ with a resulting diffusion length of $L_{\mathrm{D}} \approx 1 \mathrm{~nm}$ could explain the observed passivation effects. Such short diffusion lengths suggest that a rearrangement of hydrogen already present at or close to the interface is more likely to reduce interface dangling bonds than hydrogen migrating from the bulk of the passivation layer. Schulze et al. ${ }^{5}$ attributed such a behavior to the presence of a hydrogen-rich interfacial layer providing the majority of the passivation-active hydrogen. According to this hypothesis, film thicknesses in the device-relevant range of a few nanomenters (compared to layers of several hundred nanometers investigated here) should be sufficient for appropriate surface passivation. Experimental validation of this concept for a-Si:O:H passivation layers lies in the scope of future work. While for $c_{\mathrm{O}}=1.6 \%$ and $3.2 \%$ similarly low $S$ result, higher $c_{\mathrm{O}}$ give poorer passivation for low annealing temperatures but lead to an improved thermal stability of the passivation at higher annealing temperatures (see Fig. 9(b)).
The onset of the passivation decay shifts towards higher temperatures by about $40{ }^{\circ} \mathrm{C}$. In view of the $\mathrm{H}$ effusion results from Sec. V, this higher thermal stability may possibly be attributed to a higher $\mathrm{H}$ stability due to the presence of oxygen.

\section{Passivation improvement due to microstructural densification}

For $c_{\mathrm{O}}>5 \%$, Fig. 9(c) shows higher surface recombination velocities $S$, likely due to the emergence of a void-rich microstructure as revealed by the presence of a LT peak in $\mathrm{H}$ effusion (see Fig. 7). As discussed in Sec. V, void-rich structures allow molecular $\mathrm{H}_{2}$ to diffuse, whereas atomic $\mathrm{H}$ is unlikely to reach the $\mathrm{c}-\mathrm{Si}$ interface and to passivate interface dangling bonds. Yet, $S$ decreases and the passivation quality improves by annealing near $T_{\mathrm{A}}=400{ }^{\circ} \mathrm{C}$. We note that this temperature range correlates with the range where $\mathrm{H}$ effusion measurements suggest material reconstruction and densification to take place. Very likely, after this densification, the more compact material structure prevents hydrogen to leave the material in form of $\mathrm{H}_{2}$ via interconnected voids. As a consequence, a higher amount of diffusing atomic $\mathrm{H}$ is available for the saturation of dangling bonds at the $\mathrm{c}-\mathrm{Si}$ interface.

\section{PASSIVATION MECHANISM}

The excellent passivation properties of a-Si:O:H with $c_{\mathrm{O}}<3 \%$ raise the question of the underlying passivation mechanism. Both oxygen-free (PECVD) a-Si:H and (thermally grown) $\mathrm{SiO}_{2}$ are known to passivate c-Si surfaces well, whereas, to our knowledge, low-temperature grown stoichiometric $\mathrm{SiO}_{2}$ films generally do not.

In our PECVD a-Si:O:H films, both atomic $\mathrm{H}$ and $\mathrm{O}$ are presumably present in the initial growth phase of the layers and available for surface passivation. However, surface passivation improves during post-deposition annealing at temperatures where $\mathrm{H}$ diffuses but $\mathrm{O}$ does not. Moreover, the present results of film microstructure suggest that atomic $\mathrm{H}$ is the primary passivating species. Both the surface recombination velocity and the diffusion conditions of atomic $\mathrm{H}$ are affected by the microstructure of the passivation layer, while it appears unlikely that interface passivation by $\mathrm{O}$ (involving short $\mathrm{O}$ diffusion lengths) should be affected by the microstructure of the passivation layer.

Accepting atomic $\mathrm{H}$ as the passivating species, an efficient passivation clearly requires a fairly dense material structure close to the interface and a $\mathrm{H}$ diffusion coefficient allowing $\mathrm{H}$ atoms to move to the a-Si:O:H/c-Si interface at typical annealing temperatures. According to the present results and to those of the previous publication, in a-Si:O:H of low $\mathrm{O}$ concentration, $\mathrm{H}$ diffusion takes place with a distribution of $\mathrm{H}$ diffusion energies (see Sec. V). While the diffusion coefficient of the majority of $\mathrm{H}$ atoms decreases, for a minority of $\mathrm{H}$, the diffusion coefficient even slightly increases with $\mathrm{O}$ concentration. Presumably, this latter type of hydrogen causes the strongly improved passivation at low oxygen concentration and low annealing temperatures.

On the other hand, the diffusion of the (majority of) hydrogen atoms at higher temperatures for higher oxygen 
content (along with material densification) presumably causes the improved passivation properties of material with 7 to 10 at. $\%$ of oxygen after annealing near $400{ }^{\circ} \mathrm{C}$. The presence of interconnected voids in these materials explains the poor passivation in the as-deposited state and after annealing at low temperatures. As discussed before, ${ }^{22}$ the appearance of interconnected voids with rising oxygen content is likely related to the increasing hydrogen content, in agreement with the concept of incorporation of hydrogen at positions interrupting bonds of the amorphous network so that the network loses its connectiveness. ${ }^{31}$ Moreover, since oxygen in Si:O:H materials is not incorporated in $\mathrm{Si}-\mathrm{O}-\mathrm{H}$ but in $\mathrm{Si}-\mathrm{O}-\mathrm{Si}$ configurations, clustered oxygen even at low total oxygen content will result in the formation of silicon-oxide rings similar as in $\mathrm{SiO}_{2}$ which are known to allow diffusion of molecular hydrogen at rather low temperatures. ${ }^{32}$

\section{CONCLUSIONS}

The results demonstrate the suitability of substoichiometric silicon-oxide films for crystalline silicon surface passivation. It is found that a low oxygen content of around 1 to 5 at. $\%$ results in improved passivation properties of asdeposited material and for material annealed at temperatures below approximately $250{ }^{\circ} \mathrm{C}$, compared to a-Si:H. For higher oxygen concentrations, improved passivation is obtained only after annealing near $400^{\circ} \mathrm{C}$. These effects are attributed to a different material microstructure and, as a consequence, to different hydrogen diffusion processes. In general, the results are in agreement with diffusion of atomic hydrogen causing the passivation of crystalline silicon surface states.

\section{ACKNOWLEDGMENTS}

The authors wish to thank U. Zastrow, L. Niessen, and B. Holländer for SIMS and RBS measurements, and J. Wolff and D. Lennartz for technical support. Part of this work was supported by the German Bundesministerium für Bildung und Forschung under Contract No. 03SF0352 (Sinova).

\footnotetext{
${ }^{1}$ A. Terakawa, M. Hishida, S. Yata, W. Shinohara, A. Kitahara, H. Yoneda, Y. Aya, I. Yoshida, M. Iseki, and M. Tanaka, in Proceedings of the 26th European Photovoltaic Solar Energy Conference and Exhibition, Hamburg, Germany (WIP, Munich, 2011), pp. 2362-2365.

${ }^{2}$ D. Bätzner, Y. Andrault, L. Andreetta, A. Büchel, W. Frammelsberger, C. Guerin, N. Holm, D. Lachenal, J. Meixenberger, P. Papet, B. Rau, B. Strahm, G. Wahli, and F. Wünsch, in Proceedings of the 26th European
}

Photovoltaic Solar Energy Conference and Exhibition, Hamburg, Germany (WIP, Munich, 2011), pp. 1073-1075.

${ }^{3}$ P.-J. Ribeyron, D. Muñoz, J.-P. Kleider, W. Favre, P. Roca i Cabarrocas, M. Labrune, B. Geerligs, A. Weeber, M. Späth, C. Olson, N. Dekker, G. J. H. M. van Sark, J. A. Schüttauf, J. K. Rath, R. E. I. Schropp, M. Tucci, S. De Iullis, I. Gordon, B. O'Sullivan, A. Descoeudres, S. De Wolf, C. Ballif, T. Schultze, L. Korte, F. Madon, N. Le Quang, M. Scherff, R. Doll, Y. Zemen, and G. Zietek, in Proceedings of the 26th European Photovoltaic Solar Energy Conference and Exhibition, Hamburg, Germany (WIP, Munich, 2011), pp. 853-857.

${ }^{4}$ P. J. Rostan, U. Rau, V. X. Nguyen, T. Kirchartz, M. B. Schubert, and J. H. Werner, Sol. Energy Mater. Solar Cells 90, 1345 (2006).

${ }^{5}$ T. F. Schulze, H. N. Beushausen, T. Hansmann, L. Korte, and B. Rech, Appl. Phys. Lett. 95, 182108 (2009).

${ }^{6}$ S. De Wolf and M. Kondo, J. Appl. Phys. 105, 103707 (2009).

${ }^{7}$ T. Mueller, S. Schwertheim, M. Scherff, and W. R. Fahrner, Appl. Phys. Lett. 92, 033504 (2008).

${ }^{8}$ M. Cardona, Phys. Status Solidi B 118, 463 (1983).

${ }^{9}$ H. Wagner and W. Beyer, Solid State Commun. 48, 585 (1983).

${ }^{10}$ G. Lucovsky and W. B. Pollard, J. Vac. Sci. Technol. A 1(2), 313 (1983).

${ }^{11}$ A. A. Langford, M. L. Fleet, B. P. Nelson, W. A. Lanford, and N. Maley, Phys. Rev. B 45, 13367 (1992).

${ }^{12}$ B. G. Yacobi, R. W. Collins, G. Moddel, P. Viktorovitch, and W. Paul, Phys. Rev. B 24, 5907 (1981).

${ }^{13}$ M. H. Brodsky, M. Cardona, and J. J. Cuomo, Phys. Rev. B 16, 3556 (1977).

${ }^{14}$ M. Zacharias, T. Drüsedau, A. Panckow, H. Freistedt, and G. Garke, J. Non-Cryst. Solids 169, 29 (1994).

${ }^{15}$ L. He, T. Inokuma, Y. Kurata, and S. Hasegawa, J. Non-Cryst. Solids $\mathbf{1 8 5}$, 249 (1995).

${ }^{16}$ P. G. Pai, S. S. Chao, Y. Takagi, and G. Lucovsky, J. Vac. Sci. Technol. A 4, 689 (1986).

${ }^{17}$ A. Morimoto, H. Noriyama, and T. Shimizu, Jpn. J. Appl. Phys., Part 1 26, 22 (1987).

${ }^{18}$ G. Lucovsky, J. Yang, S. S. Chao, J. E. Tyler, and W. Czubatyj, Phys. Rev. B 28, 3225 (1983).

${ }^{19}$ D. V. Tsu, G. Lucovsky, and B. N. Davidson, Phys. Rev. B 40, 1795 (1989).

${ }^{20}$ L. Schumann, A. Lehmann, H. Sobotta, V. Riede, U. Teschner, and K. Hübner, Phys. Status Solidi B 110, K69 (1982).

${ }^{21}$ F. Einsele, W. Beyer, and U. Rau, Phys. Status Solidi C 7, 1021 (2010).

${ }^{22}$ W. Beyer, J. Non-Cryst. Solids 266-269, 845 (2000).

${ }^{23}$ W. Beyer and F. Einsele, in Advanced Characterization Techniques for Thin Film Solar Cells, edited by D. Abou-Ras, T. Kichartz, and U. Rau (Wiley-VCR, Weinheim, 2011), p. 449.

${ }^{24}$ W. Beyer, S. S. Camargo, and R. Saleh, Mater. Res. Soc. Symp. Proc. 609, A23.4 (2000).

${ }^{25}$ W. Beyer and H. Wagner, J. Appl. Phys. 53, 8745 (1982).

${ }^{26}$ N. P. Kherani, B. Liu, K. Virk, T. Kosteski, F. Gaspari, W. T. Shmayda, S. Zukotynski, and K. P. Chen, J. Appl. Phys. 103, 024906 (2008).

${ }^{27}$ R. A. Sinton and A. Cuevas, Appl. Phys. Lett. 69, 2510 (1996).

${ }^{28}$ A. B. Sproul, J. Appl. Phys. 76, 2851 (1994).

${ }^{29}$ H. Fujiwara and M. Kondo, Appl. Phys. Lett. 90, 013503 (2007).

${ }^{30}$ R. W. Collins and B. Y. Yang, J. Vac. Sci. Technol. B 7, 1155 (1989).

${ }^{31}$ W. Beyer and H. Wagner, J. Non-Cryst. Solids 59-60, 161 (1983).

${ }^{32}$ F. J. Norton, J. Am. Ceram. Soc. 36, 90 (1953). 